слушатель 2-го факультета

Академии управления МВД России

\section{СТРУКТУРНО-ФУНКЦИОНАЛЬНЫЙ ПОДХОД КАК ОСНОВА ЭФФЕКТИВНОЙ ДЕЯТЕЛЬНОСТИ ОРГАНОВ ВНУТРЕННИХ ДЕЛ (НА ПРИМЕРЕ УДМУРТСКОЙ РЕСПУБЛИКИ)}

Аннотация:

Статья посвящена актуальной проблеме функционирования системы органов внутренних дел (ОВД) Российской Федерации в условиях реформирования u c учетом действующего законодательства, направленного на обеспечение общественного порядка и безопасности страны, профилактику преступности, защиту граждан и организаций от противоправных посягательств. Структурно-функциональный подход способствует не только изучению структуры организации, но и ее функционированию, выполнению возложенных на нее целей и задач, а также извлечению результатов деятельности изучаемого объекта. В статье представлен правовой аспект реформирования ОВД, на основе структурно-функционального подхода в соответствующей организации предложены направления ее оптимизации, определены возможные пути развития данного подхода (на примере Удмуртской Республики). Рассмотрены работы специалистов о применении структурного и функционального подходов к исследованию организации. Автором сделаны выводы о необходимом повышении эффективности деятельности в ОВД, где важное место занимает совершенствование организации управления и выполнение сопутствующих задач. В их числе целесообразная расстановка кадров и должное использование кадрового потенциала; обеспечение анализа реального состояния оперативной обстановки, своевременной выработки и реализации решений по ее нормализации; упорядочение процессов бюджетирования и распределения ресурсов; сокращение параллельных и дублирующих звеньев; рост доверия населения к полиции в целом.

Ключевые слова:

структурный и функциональный подход к исследованию организации, административная реформа, правовая основа реформирования органов внутренних дел, повышение эффективности деятельности полиции, охрана правопорядка, доверие граждан, МВД России, МВД по Удмуртской Республике, Удмуртская Республика.
Student, 2nd Department, Academy of Management of the Ministry of Internal Affairs of Russia

\section{A STRUCTURAL AND FUNCTIONAL APPROACH AS A BASIS FOR THE EFFECTIVE ACTIVITIES OF INTERNAL AFFAIRS BODIES (A CASE OF THE UDMURT REPUBLIC)}

\section{Summary:}

The paper deals with the internal affairs bodies functioning in the Russian Federation in the context of reforms and current legislation on public order and security of the country, crime prevention, protection of citizens and organizations from illegal encroachments. A structural and functional approach helps examine the structure of internal affairs agencies, their perfor mance, the achievement of their goals and objectives, the results of their activities. The research describes the legal aspect of reforming the internal affairs bodies, determines the area of their improvement on the basis of the structural and functional approach, and identifies ways to develop this approach (by a case study of the Udmurt Republic). The authors consider the works on the use of such an approach to studying the organization. In the authors' opinion, it is necessary to increase the efficiency of internal affairs bodies, improve their management, and address the relevant challenges. They include a suitable staff deployment and the proper use of human capacity; the analysis of current operational situation and solutions to improve it; the proper allocation of funds and resources; the abolishment of duplicative departments; the increased public trust in the police as a whole.

В условиях реформирования системы органов внутренних дел вопрос их функционирования и организационной структуры представляется особенно значимым. Структурно-функциональный подход дает возможность применять методы опережающего анализа, направленные на совершенствование механизма ограничения и снятия структурно-функциональных отклонений в системе ОВД, что способствует большей результативности деятельности, приведению в соответствие с ее правоохранительным назначением.

В настоящее время применение структурно-функционального подхода в организации системы ОВД позволяет выявить недостатки в этой сфере и предложить направления совершенствования ввиду продолжающейся ее реформы в Российской Федерации, что считается одним 
из главных условий эффрективной борьбы с преступностью, обеспечения правопорядка и общественной безопасности. Проблемам, связанным с использованием структурного и функционального подходов к исследованию организации, выявлением их роли в этом процессе, посвящено немало работ. Рассматриваемые нами в статье вопросы базируются на социологическом подходе, представленном в трудах Т. Парсонса, А. Рэдклифрф-Брауна и др. [1]. Указанные проблемы привлекали внимание ученых, исследовавших различные аспекты социологии и теории управления. Среди них - В.Г. Вишняков, Г.В. Атаманчук и ряд других [2]. Структурный и фуннциональный подходы в общесистемном и общенаучном плане, в их применении находят отражение, в частности, в работах Н.Т. Абрамовой, Ю.Г. Маркова [3].

Учитывая актуальность вопроса качества деятельности различных организаций, приоритетными направлениями сегодня являются изучение и построение их структурно-функциональной модели, оценка ее эффрективности. Отдельную группу составляют исследования В.Б. Коробова, В.А. Ребрий и других [4], характеризующие организационную и функциональную структуру ОВД. В трудах А.П. Ипакяна, С.С. Маиляна раскрываются проблемы в области выработки, принятия и реализации решений в ОВД [5]. Итак, анализ литературы в контексте темы настоящей статьи показывает, что структурно-фуннццональный подход в целом специалистами исследуется в той или иной степени, но проблема соотношения функционального и структурного подходов в организации системы ОВД не изучена в полном объеме.

Начало проведения административной реформы по совершенствованию государственного аппарата восходит к 2003 г. Не осталась в стороне от нее система ОВД Российской Федерации как органа государственного управления. Приоритетным направлением деятельности органов внутренних дел была оптимизация системы управления, формирование структуры, штатной численности ОВД и внутренних войск МВД России [6]. Реформы в исследуемой нами сфере начались с момента издания Указа Президента Российской Федерации от 24 декабря 2009 г. № 1468 «О мерах по совершенствованию деятельности органов внутренних дел Российской Федерации» [7]. Этот и последующие документы определили программу мер по увеличению бюджета ассигнований, направленных на дополнительное денежное стимулирование сотрудников, развитие кадрового потенциала, улучшение жилищных условий сотрудников, проведение действенной антикоррупционной политики в системе МВД, формирование объективной и научно обоснованной системы оценки эффрективности деятельности ОВД, внедрение современных технологий. Не случайно принят Указ Президента России от 18 февраля 2010 г. № 208 «О некоторых мерах по реформированию Министерства внутренних дел Российской Федерации» [8], связанный с исключением дублирующих, избыточных и не свойственных милиции (полиции) функций, а также оптимизацией структуры и численности работников МВД. Во время реформирования сохранена вертикаль централизованного управления в системе МВД, а также принят ряд законодательных актов (федеральные законы «О полиции», «О социальных гарантиях сотрудникам органов внутренних дел Российской Федерации и внесении изменений в отдельные законодательные акты Российской Федерации» [9] и др.), соответствующих международным стандартам работы полиции.

В современных условиях по-прежнему актуальны задачи организации эфффективной системы ОВД, в частности деятельности полиции, призванной защищать права и интересы населения, обеспечивать безопасность, правопорядок, охрану общественного порядка. В центре внимания в сфере вопросов организационной структуры ОВД - централизация и децентрализация управления, конкретизация его функций и полномочий. Не все задачи решены при функционально-структурном совершенствовании данной системы. Среди основных проблем - нарушение законности, дисциплины в рядах сотрудников правопорядка, невысокое качество правоохранительных услуг, не на должном уровне и доверие граждан к полиции. В числе ведущих направлений работы с применением структурно-функционального подхода такие, как повышение кадрового профессионализма, борьба с коррупцией, открытость правоохранительных органов и укрепление доверия к ним со стороны населения, эффективность системы управления и деятельности ОВД, доступность правоохранительной помощи, а также профилактика преступности.

Особенно важным вопросом представляется решение существующих кадровых проблем. В ходе реформы системы МВД с 2011 г. в Удмуртской Республике ликвидирован фрилиал Нижегородской академии МВД России, где осуществлялась подготовка кадров сферы правоохранительной деятельности. Сегодня будущие полицейские из Удмуртии уезжают на учебу в другие профильные учебные заведения. К сотрудникам полиции предъявляются достаточно высокие профессиональные требования: возрастные ограничения, российское гражданство, состояние здоровья, образовательный ценз. Согласно российскому законодательству ряд вакансий предусматривает высшее юридическое образование. Повышение требований к такому критерию профессионализма, как образовательный ценз, приводит к «кадровому голоду», проявляющемуся в разных районах республики. 
В ходе реформирования произошло сокращение численности сотрудников правопорядка, что отрицательно повлияло на получение гражданами правоохранительной помощи и отчасти сказалось на снижении доверия к полиции со стороны населения. Возможности решения соответствующих проблем, на наш взгляд, представлены в сфере поиска и внедрения новых форм деятельности полицейских, в том числе таких, как использование современных технических средств, укрепление взаимодействия с общественными объединениями правоохранительной направленности (например, добровольными народными дружинами). В частности, в Удмуртской Республике граждане принимают активное участие в охране общественного порядка, что заметно сокращает процент преступлений, совершаемых в общественных местах. Так, в г. Ижевске с 1996 г. действует добровольная народная дружина «Дорожный патруль». Ее цель - оказание помощи инспекторам ГИБДД в дежурстве на дорогах в выходные и праздничные дни, при проведении массовых городских мероприятий. Статистика показателей их деятельности позволяет сделать вывод о позитивных изменениях в данной сфере. Если в 2014 г. с участием народных дружин проведено 704 рейда и пресечено 800 административных правонарушений, то в 2017 г. количество рейдов составило 1 985, пресечено 2447 административных правонарушений [10]. Несмотря на некоторые успехи, не стоит переоценивать подобное сотрудничество с населением. Существует ряд проблем, связанных, во-первых, с недостаточным финансированием соответствующих объединений (дружин), во-вторых, с отсутствием в этой сфере работающих на практике нормативных документов.

Полагаем, что необходимо продолжить развитие основных служб и подразделений ОВД, применять в отношении них обоснованное сокращение дублирующих звеньев, освобождать от исполнения несвойственных им функций. Известны случаи, когда сотрудники, отвлекаясь от непосредственных полномочий, вынуждены выполнять ряд других задач, например, в период охраны избирательных участков. По статистике, в предыдущем году безопасность на избирательных участках в рамках избирательной кампании обеспечивали почти 90 тысяч сотрудников [11].

Принятие решений в анализируемой нами сфере должно опираться на изучение и глубокий анализ передового опыта, мнение практиков и ветеранов, а также общественности. Приоритетные направления в процессе совершенствования организационных структур в системе МВД России это прежде всего укрепление подразделений, призванных решать задачи практического характера, находящихся на переднем крае борьбы с преступностью, оптимизация административного аппарата и обеспечивающих служб. В частности, сотрудников так называемых вспомогательных структур (например, тыловых и кадровых подразделений, культурных центров), как нам кажется, следует перевести в статус госслужащих или вольнонаемных работников, поскольку, во-первых, они не выполняют непосредственно функции полицейских; во-вторых, это способствует экономии и высвобождению ставок для сотрудников, работающих «на земле».

Охарактеризуем проблему дублирования полномочий в системе ОВД на примере Управления МВД России по г. Ижевску. Его предшественник - Управление внутренних дел г. Ижевска, после ликвидации которого в 1998 г. отделы милиции этого города перешли в подчинение МВД Удмуртской Республики и общее руководство ими осуществлял заместитель МВД Удмуртской Республики. В 2009 г. вновь создано Управление внутренних дел по г. Ижевску, а в 2011 г. оно переименовано в Управление МВД Российской Федерации по г. Ижевску [12] - учреждение, во многом дублирующее полномочия Министерства внутренних дел. Несмотря на то что функции и полномочия, указанные в Положениях различных ведомств, нередко имеют различные фоомулировки, они несут одинаковую смысловую нагрузку. Это позволяет осуществлять полномочия территориальным органам МВД Российской Федерации на уровне региона, минуя УМВД России по городу. Поэтому своевременным становится вопрос о необходимости сокращения УМВД России по г. Ижевску.

Нельзя не учитывать потребность в выработке оптимальной системы в сфере деятельности подразделений по борьбе с организованной преступностью, а также задачи оперативноразыскных подразделений ГУ МВД России в федеральных округах. Важно уделить пристальное внимание направлению работы по розыску пропавших без вести, сократить и в дальнейшем исключить из практики случаи отказа в регистрации заявлений об исчезновении граждан. Следует, по нашему мнению, укомплектовать разыскные подразделения подготовленными оперативными работниками, расширить возможности компьютерных технологий для оперативного информирования населения об исчезнувших, интенсивнее привлекать к работе волонтеров. Так, продолжается сотрудничество полиции в регионах с поисковым отрядом добровольцев «Лиза Алерт». Его основная задача - оказание оперативной помощи в поиске пропавших детей. На территории Удмуртской Республики успешно работает поисково-спасательный отряд «Регион 18», который также старается помочь правоохранительным органам в поиске пропавших людей.

Существенным является и вопрос о целесообразности внедрения в работу Главного управления уголовного розыска МВД России и Управления уголовного розыска МВД республик, УМВД 
субъектов Российской Федерации передовых технологий розыска пропавших, которые применяет американский Международный центр помощи пропавших и эксплуатируемых детей - ICMEC (г. Александрия, штат Вирджиния). Этот центр способствует улучшению систем защиты детей от похищения и сексуального насилия в мире, а его представители считают, что стратегия по работе с проблемой пропажи и эксплуатации детей должна выходить за рамки законодательного поля. ICMEC разработал Модельную рамочную программу помощи пропавшим детям, содержащую законоположения, практические методики и комплексные меры [13].

Таким образом, функционально-структурное совершенствование любой социальной системы, в том числе системы ОВД, - это перманентный процесс, зависящий от состояния и уровня социально-экономического развития общества и государства. Полагаем, что все изменения должны происходить планомерно, соответствовать целям и задачам организации, направленным на повышение эффрективности деятельности.

\section{Ссылки:}

1. Parsons T. The System of Modern Societies. New Jersey, 1971. 152 p. ; Radcliffe-Brown A. Structure and Function in Primitive Society. Glencoe, 1952. 219 p.

2. Атаманчук Г.В. Теория государственного управления : учебник. М., 2014. 525 с. ; Вишняков В.Г. Система и структура федеральных органов исполнительной власти: теория и практика // Журнал российского права. 2006. № 8 (116). С. 67-83.

3. Абрамова Н.Т. Целостность и управление. М., 1974. 248 с. ; Марков Ю.Г. Функциональный подход в современном научном познании. Новосибирск, 1982. 255 с.

4. Коробов В.Б., Ребрий В.А. Механизм оценки конечных социально значимых результатов деятельности органов внутренних дел с учетом воздействия фракторов внешней среды // Труды Академии управления МВД России. 2015. № 4 (36). C. 17-21.

5. Ипакян А.П. Оценка эффрективности деятельности органов внутренних дел в механизме их реформирования // Труды Академии управления МВД России. 2007. № 4. С. 47-52 ; Кикоть В.Я. Наука управления. Основы организации и управления в правоохранительной деятельности. М., 2015. 751 с.

6. Филимонов О.В. Функциональный анализ структуры управления социальной сферой внутренних войск МВД России на современном этапе // Труды Академии управления МВД России. 2012. № 1 (21). С. 73-78.

7. О мерах по совершенствованию деятельности органов внутренних дел Российской Федерации : указ Президента РФ от 24 дек. 2009 г. № 1468 // Российская газета. 2009. № 251. 28 дек.

8. О некоторых мерах по реформированию Министерства внутренних дел Российской Федерации : указ Президента РФ от 18 февр. 2010 г. № 208 // Там же. 2010. № 36.19 февр.

9. О полиции : федер. закон РФ от 7 февр. 2011 г. № 3-ФЗ // Собрание законодательства РФ. 2011. № 7. Ст. 900 ; О социальных гарантиях сотрудникам органов внутренних дел Российской Федерации и внесении изменений в отдельные законодательные акты Российской Федерации : федер. закон РФ от 19 июля 2011 г. № 247-Ф3 // Российская газета. 2011. № 157. 20 июля.

10. В 2017 году народные дружинники городов и районов Удмуртии оказали содействие в раскрытии более 70 преступлений [Электронный ресурс] : офиц. сайт Главы Удмуртской Республики и Правительства Удмуртской Республики. URL: http://www.udmurt.ru/about/info/news/?ELEMENT ID=318276 (дата обращения: 16.08.2018) ; Отчет министра внутренних дел по Удмуртской Республике перед Государственным Советом Удмуртской Республики о деятельности органов внутренних дел в 2014 году [Электронный ресурс] // Министерство внутренних дел по Удмуртской Республике : офиц. сайт. URL: http://18.xn--b1aew.xn--p1ai/document/3073236 (дата обращения: 16.08.2018).

11. Расширенное заседание коллегии МВД России [Электронный ресурс] : офиц. сайт Президента России. URL: http://kremlin.ru/events/president/news/56949 (дата обращения: 16.06.2018).

12. Вопросы Управления Министерства внутренних дел Российской Федерации по г. Ижевску [Электронный ресурс] : приказ Министерства внутренних дел по Удмуртской Республике от 1 июля 2011 г. № 371. URL: https://xn--b1afchn5b.18.xn--b1aew.xn--p1ai/folder/6561946 (дата обращения: 24.08.2018).

13. Пособие по оценке передового опыта решения проблемы пропавших детей и рекомендации в данной сфере [Электронный ресурc]. 2016. URL: https://www.icmec.org/wp-content/uploads/2016/10/MCRP US-RussiaP2P RU.pdf (дата обращения: 16.08.2018).

\section{References:}

Abramova, NT 1974, Integrity and Management, Moscow, 248 p., (in Russian).

Atamanchuk, GV 2014, Theory of Public Administration: a textbook, Moscow, 525 p., (in Russian).

Filimonov, OV 2012, 'Functional Analysis of the Management Structure of the Social Sphere of the Internal Troops of the Ministry of Internal Affairs of Russia at the Present Stage', Trudy Akademii upravleniya MVD Rossii, no. 1 (21), pp. 73-78, (in Russian).

Handbook on the Assessment of Best Practices for Solving the Problem of Missing Children and Recommendations in This Area

2016, viewed 16 August 2016, <https://www.icmec.org/wp-content/uploads/2016/10/MCRP US-RussiaP2P RU.pdf>, (in Russian). Ipakyan, AP 2007, 'Assessment of the Effectiveness of the Activities of the Internal Affairs Bodies in the Mechanism of Their Reform', Trudy Akademii upravleniya MVD Rossii, no. 4, pp. 47-52, (in Russian).

Kikot, VYa 2015, Management Science. Fundamentals of Organization and Management in Law Enforcement, Moscow, 751 p., (in Russian).

Korobov, VB \& Rebry, VA 2015, 'The Mechanism for Assessing the Ultimate Socially Significant Results of the Work of the Internal Affairs Agencies, Taking into Account the Impact of Environmental Factors', Trudy Akademii upravleniya MVD Rossii, no. 4 (36), pp. 17-21, (in Russian).

Markov, YuG 1982, Functional Approach in Modern Scientific Knowledge, Novosibirsk, 255 p., (in Russian).

Parsons, T 1971, The System of Modern Societies, New Jersey, 152 p.

Radcliffe-Brown, A 1952, Structure and Function in Primitive Society, Glencoe, $219 \mathrm{p}$.

Vishnyakov, VG 2006, 'The System and Structure of Federal Executive Bodies: Theory and Practice', Zhurnal rossiyskogo prava, no. 8 (116), pp. 67-83, (in Russian). 